Article

\title{
Climate Adaptation as Organizational Learning: A Grounded Theory Study on Manufacturing Companies in a Bavarian Region
}

\author{
Sophie Fischer ${ }^{1, * \mathbb{D}}$, Luzia Keupp ${ }^{2}$, Heiko Paeth ${ }^{2}$, Michael Göhlich ${ }^{3}$ and Jan Schmitt ${ }^{1}$ D \\ 1 Institute Digital Engineering, University of Applied Sciences, Ignaz-Schon-Street 11, \\ 97421 Schweinfurt, Germany; jan.schmitt@fhws.de \\ 2 Institute for Geography and Geology, Julius Maximilians University, Sanderring Street 2, \\ 97070 Würzburg, Germany; luzia.keupp@uni-wuerzburg.de (L.K.); heiko.paeth@uni-wuerzburg.de (H.P.) \\ 3 Department of Education, Friedrich Alexander University, Bismarckstr. 1a, 91054 Erlangen, Germany; \\ michael.goehlich@fau.de \\ * Correspondence: xeniasophie.fischer@fhws.de
}

Citation: Fischer, S.; Keupp, L.; Paeth, H.; Göhlich, M.; Schmitt, J. Climate Adaptation as Organizational Learning: A Grounded Theory Study on Manufacturing Companies in a Bavarian Region. Educ. Sci. 2022, 12, 22. https://doi.org/10.3390/ educsci12010022

Academic Editor: James Albright

Received: 22 November 2021

Accepted: 28 December 2021

Published: 1 January 2022

Publisher's Note: MDPI stays neutral with regard to jurisdictional claims in published maps and institutional affiliations.

Copyright: (C) 2022 by the authors. Licensee MDPI, Basel, Switzerland. This article is an open access article distributed under the terms and conditions of the Creative Commons Attribution (CC BY) license (https:// creativecommons.org/licenses/by/ $4.0 /)$.

\begin{abstract}
Climate adaptation supports organizations in dealing with the current and projected effects of climate change by recognizing challenges as opportunities and increasing their economic efficiency. Based on the regional climate model REMO and 13 expert interviews with representatives from mainly manufacturing companies analyzed by the Grounded Theory methodology, this contribution aims to outline actual and future challenges of climate adaptation in the investigated region. We analyze how manufacturing companies respond to climate change and assess the main promoters and barriers of organizational learning in the context of climate adaptation. The expert interviews confirm the importance for companies of having a concrete business case for any strategies and of increasingly making their processes and manufacturing more transparent, through supply chain assessments. In accordance, a focus on strategic management levels is crucial for organizational learning processes as they are responsible for development, mobilization of resources and realization of adaptation concepts.
\end{abstract}

Keywords: climate adaptation; organizational learning; grounded theory; change management; manufacturing companies

\section{Introduction}

Since 1880 , the average surface temperature has increased by approximately $1{ }^{\circ} \mathrm{C}$, and the atmospheric $\mathrm{CO}_{2}$ concentration has increased by $46 \%$ to $413.3 \mathrm{ppm}$ [1,2]. These climatic and atmospheric changes cause elevated incidence rates of extreme weather and natural disasters, which in turn lead to multiple negative effects on ecological and economical systems [3-5]. Besides all current efforts to cope with climate change, global greenhouse gas emissions are increasing enormously [6] due to the current focus on efficiency, growth and speed of manufacturing practices. In 2019 , global carbon dioxide $\left(\mathrm{CO}_{2}\right)$ emissions amounted to 36.4 billion tons of carbon dioxide, which is the highest level since 1960 [1]. Germany produces 9.2 tons of greenhouse gas emissions per capita annually, which is approximately twice the global average per capita [7]. Especially, the manufacturing industry contributes significantly to climate change. Besides the energy sector, the industrial sector produces the second-highest $\mathrm{CO}_{2}$ emissions [8]. Especially, the local manufacturing industry causes around $24 \%$ of emissions recorded nationwide (ibid.). The northwestern Bavarian region Lower Franconia is characterized by its economic diversity, and simultaneously it is a "hotspot of climate change" [9]. Since 1947, a warming of $1.1^{\circ} \mathrm{C}$ (in summer) and $1.4{ }^{\circ} \mathrm{C}$ in winter has been recorded $[9,10]$. The current and predicted warming rates are considerably higher than the global and German national averages [2]. Based on the Representative 
Concentration Pathways (RCPs), the latest research projects a warming of between $2.7^{\circ} \mathrm{C}$ and $4.4^{\circ} \mathrm{C}$ for the region by the next century [11]. Within this projection, several negative impacts on the economic ecosystem are likely $[1,12]$.

To prevent future damage and take advantage of new adaptation opportunities, companies should develop their own sophisticated business strategies. Furthermore, besides being driven by prosperity, they must optimize their behavior, sense of responsibility and their negative impact on nature and the climate. Nevertheless, there is no discernible tendency among manufacturing companies to strategically address climate mitigation and adaptation [13]. As organizational learning is a key element to promote economic development in economically uncertain circumstances, we analyze organizational learning related to climate adaptation and develop tools to enable local companies in developing own adaptation strategies in our project. Further, we intend to make companies aware of their responsibility in the face of climate and environment.

In accordance with the criterion method of triangulation, two approaches for data collection will be used: regional climate data and expert interviews according to the Grounded Theory methodology. The Grounded Theory methodology promises a more intensive and substantial abstraction of theories from empirical data due to its detailed and analytical procedure. Hence, we develop a conceptual model based on Grounded Theory that illustrates learning-enhancing and learning-inhibiting elements in the context of climate adaptation. Our approach relies on the assumption that global climate change and climate adaptation is often still a complex and abstract topic for organizations beyond the primary sector (e.g., agricultural industry). We attempt to bridge this natural distance by using a synthesis of scientific disciplines. Here, we contrast climate data and projections with subjective perceptions of (affected) economic actors. From a pedagogical perspective, we analyse the learning processes that are constituted within climate adaptation. Subsequently, implications regarding climate adaptation for economic actors and additional studies are derived. Our findings are dedicated to support the target group in viewing current and future environmental influences in a constructive way and anticipate their further economical risks. In addition, the conceptual examination of the terms climate adaptation and organizational learning will be explained.

\section{Theoretical Background}

Generally, current scientific research in the field of climate adaptation is dominated by research with an urban, regional, or municipal focus [14,15]. Numerous guidelines for climate adaptation have emerged [16], although it is also apparent here that companies have so far played a secondary role compared to policymakers. With the increase by a factor of 3.81 ("climate adaptation" + "economy") respectively 1.91 ("climate adaptation" + "organizational learning"), from 2010 to 2021, the exemplary keyword search in Google Scholar illustrates the rising engagement of research in this field. Researchers worldwide record adaptation efforts of companies, especially manufacturing companies [17-20], and they analyze to what extent organizational learning enables organizations to maintain efficiency in a situation that is economically unpredictable [20-22]. The management level is frequently addressed in these studies as it is decisive for the development, provision of resources and implementation of adaptation concepts as well as being considered as drivers [20]. Current scientific research also reflects the described limited applicability of climate adaptation approaches. Various approaches are based on the assumption that the topic of climate adaptation will become more prominent in the future and must be promoted by politics, science $[4,23,24]$, and in particular, by management [17].

\subsection{Importance of Climate Adaptation}

To deal with impacts and uncertainties of climate change, organizations should constantly identify their individual challenges (physical, mark-regulatory, human, etc.) and design measures to meet them. With regard to increasing requirements such as reduction targets, energy taxation, and supply chain assessment, manufacturing companies face the 
challenge of initiating effective adaptation strategies. Two decades ago (year 2000), climate adaptation in Germany was still deemed an "undesirable distraction" in the development of an effective energy policy for climate mitigation [25]. Nowadays, the importance of adaptation to climate change is increasing. Nevertheless, climate adaptation only slowly turns into a management topic [17]. One reason for the topic-related increase in engagement may be the rise in funding from the federal government that should provide incentives for companies to rethink and initiate or derive new approaches and measures [25]. In addition, it may be induced by the interrelation between climate mitigation and adaptation. Both approaches aim to generate positive effects by seizing opportunities and resilience as well as preventing human and economic damages. Mitigation and adaptation measures influence each other, meaning they have a reciprocal effect. Climate mitigation refers to the goal of reducing anthropogenic greenhouse gas emissions and is effective worldwide irrespective of geographic boundaries. Climate adaptation has a local effect and refers to initiated measures and changed patterns of behavior to adapt to environmental changes. According to the Intergovernmental Panel on Climate Change (IPCC), climate adaptation is defined in two ways: first, to prevent economic damage and second to increase economic effectiveness [26]. Measures of climate adaptation have an effect at different points. Anticipatory measures include energy-saving planning and realization of new buildings including technological protection equipment (e.g., installation of snow guards on roofs). Reactive measures follow the direction of responding to a concrete challenge, e.g., offering the employees drinks and enough time for breaks on hot days.

Originally associated with evolutionary considerations [27], the term adaptation in an organizational context covers the ability and volition of organizations to deal with external changes, to anticipate future developments, and to align their own structures and processes with these changes continuously. Anticipatory and reactive adaptation measures and modified behaviors will protect the company from the actual and predicted consequences arising from climate change. The intention is to cope with occurring challenges and to preserve business effectiveness. Further, organizational adaptation processes involve learning.

\subsection{Importance of Organizational Learning}

Organizational learning is a key element for organizations to evolve and sustain themselves in a dynamic, complex environment and face continual challenges and uncertainties [28-30]. Although the concept of "learning" is influenced by behaviorism and cognitive psychology in many instances and focuses on individual learning, there is learning in, by and among organizations, which proves to be more challenging to measure and analyze [31]. The term "Organizational Learning", which partly has been coined (ibid.) by [32-34], contains a few key elements to be outlined.

Argyris and Schön [32] describe an approach the learning process into theories of action carried out by individual members and that differentiates into three modes. Singleloop learning implies simple (operative) recognition and correction of errors or misguided processes. Double-loop learning means recognizing and correcting mistakes is not enough; instead, specific theories of action must be modified. This mode involves redefining existing rules and norms. The term deutero-learning indicates that organizations not only learn for a limited period of time; instead, it is a process. This mode of reflective learning requires that organizations consider the conditions needed to make the processes of single-loop and double-loop learning more effective and to determine how these processes can be induced.

Referring to the behaviorist understanding of learning, i.e., behavioral change as a result of external stimuli, March et al. [33,35] define organizational learning as an adaptation process. Organizations learn from experiences which they observe, reflect and modify for subsequent actions (ibid.). Senge's book "fith discipline" guides many modern management theories and it is more "praxeological" than other learning theories [35]. Referring to systems thinking, Senge defines learning as a rethinking process. Here, he indicates the five core disciplines of personal mastery, mental models, shared vision, and team learning [36]. His assumption is that organizational learning is initially a theoretical 
construct or vision which is driven by organizational members in a processual manner by evolving successively to achieve their goals (ibid.) .

It becomes apparent that organizational learning is constituted through an interplay of learning objects, learning agents and various modes. Focusing solely on learning from a cognitivist perspective leaves out content-related aspects such as ability learning, life learning, and learning to learn [31]. One challenge is that only "knowledge-learning" becomes accessible for studies conducted by expert interviews or questionnaires while the other components are rather accessible for studies using merely qualitative methods such as observations, especially over a longer period of time (ibid.). In addition to the capacity for organizational learning, changed processes and organizational structures are required accordingly. In this context, Marsick [37] defined several indicators that an organization needs to adapt effectively to dynamic organizational environments. Besides the underlying organizational conditions, they list internal and external communication, innovativeness, collective learning, and the accumulation of knowledge and expertise as core elements. Generally relevant in the context of organizational learning is, as Göhlich [31] states, to assume a responsibility to the learning object, which here is climate adaptation. Consequently, the organizational genesis of knowledge and ability is constituted dialogically with the learning object, with responsibility towards the environment and co-environment and in accordance with the individual capacities, motivation and competencies of learning actors (here specifically the organizations and their members). Genuinely, an organization learns through its members, the "catalysts of change" [21] who learn individually and collectively or by means of "organizational cultural islands" [31]. Therefore, learning implies specific changes in mental models (e.g., the so-called organizational images and maps according to Argyris and Schön [32] in which processes, structures and actions are processed in a reflexive and mimetic manner. A further key element for organizational learning is the organizational culture. The organizational culture is a set of values and norms that evolved over time and forms the foundation for members' communication, attitudes, guiding principles, and actions $[38,39]$. It conserves past learning processes but is affected by individuals learning experiences as well as their changing values and attitudes [38].

The uncertain economic conditions require organizations which accept the altered needs and challenges and adapt their structures, targets and strategies according to dynamic external changes [37]. Even more, the objectives for organizations today might not only be continuous growth, increased performance and revenue but also creating social impact, i.e., making a contribution to the preservation and further development of society and the economy (see [40]). Overall, climate adaptation as organizational learning requires organizations' continuous movement and realignment. Organization and members adapt to external changes by creating processes, interactions, and products in an anticipatory and responsive manner, by capturing lessons learned and experiences and communicating them to all members, as well as by creating explicit learning spaces and times. Those will support a collaborative, reflective, and communicative learning process for members.

\section{Methods}

The research design for the present study is based on mixed methods and includes regional climate model projections as well as 13 expert interviews with manufacturing companies, reflecting the perceived climate change from an economic perspective. Accordingly, using high-resolution climate models, business, political and social actors will be able to derive anticipatory adaptation strategies in the future. We investigate the following research questions (RQ):

1. RQ: How is climate in the study region projected to develop until the end of the 21st century, particularly with respect to extreme events? (Regional climate model)

2. RQ: To what extent is climate adaptation organizational learning and what are the promoters and barriers? (Expert interviews)

Although the two research questions each addresses a specific discipline, RQ1 regional climate data, climatological, and RQ2 organizational learning, pedagogical, they cannot 
be treated separately from each other. One reason for this is that the present contribution intended to illustrate the relevance of climate adaptation. Our climate data will beused as a starting point to define the vulnerability and affectedness of the companies. On the other hand, our approach aims to inspire other researchers in their studies to consider the factor interdisciplinarity within the discourse of climate adaptation more. Until now, related studies on climate adaptation have tended to focus on one-dimensional analyses of the phenomenon. Here, for example, the promoting and inhibiting elements of climate adaptation are analyzed [17,19,22,23], levels of management are discussed more closely $[18,24,41]$, or correlations between climate adaptation and organizational learning are emphasized $[4,20,21]$. However, since organizational actors are economically driven, climate adaptation usually occurs only after a concrete incident or a new legal requirement, as evidenced by the interviews (see Section 4.3). To enable data-driven decisions to adapt to Climate Change by organizations in a dynamic way and to implement new processes and structures already before a concrete incident, regional climate data are an effective tool. This insight needs to be addressed by the scientific discourse, as science makes a relevant contribution to the transfer of knowledge and technology and to the further development of a society.

In the following two subsections, the specific research designs of the regional climate analysis as well as the expert interviews are explained.

\subsection{Regional Climate Model Data}

The regional climate model REMO in its current version [42,43] was mainly developed at the Climate Service Center Germany (GERICS) and is part of the EURO-CORDEX (European part of Coordinated Downscaling Experiment) project with $0.11^{\circ}(12.5 \mathrm{~km})$ as the highest resolution currently available. The dynamical downscaling is particularly based on a higher resolution of physical processes as well as surface patterns and variables $[44,45]$. Figure 1 shows a visual impression of the added value of regional compared to global climate models.

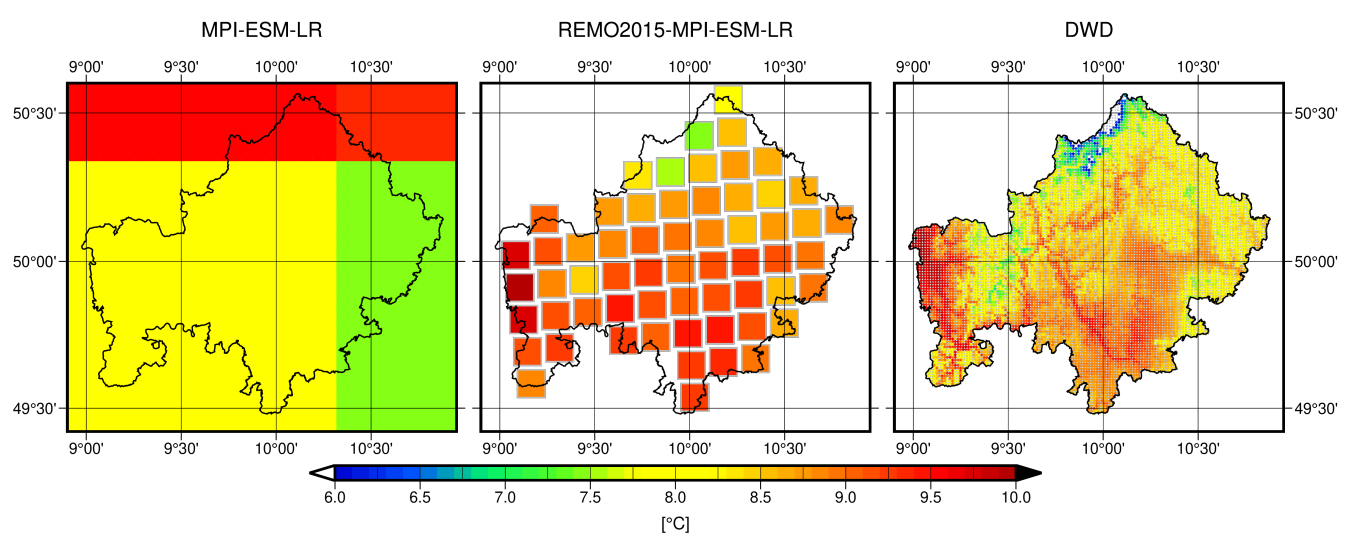

Figure 1. Mean near-surface temperature 1970-1999 in Lower Frankonia. MPI-ESM-LR (left, resolution ca. $180 \mathrm{~km}$ ), REMO2015 driven by MPI-ESM-LR (middle, ca. $12.5 \mathrm{~km}$ ), gridded observations of the German Weather Service (right, $1 \mathrm{~km}$ ) [46]. 
The driving model MPI-ESM-LR is part of the Coupled Model Intercomparison Project phase 5 (CMIP5) [47] which sets up the basis for the 5th assessment report of the Intergovernmental Panel on Climate Change (IPCC AR5) [48]. Future climate is projected using the Representative Concentration Pathways (RCPs) [49,50]. Here, we apply the scenario RCP8.5 [51], which includes the highest greenhouse gas emissions of all RCPs but reflects the currently still missing effort in international climate protection policy [52]. The following indices are calculated for late-20th (1970-1999, historical climate forcing agent), mid-21st (2040-2069) as well as late-21st (2070-2099) century (RCP8.5 scenario) climate projections using daily mean near-surface temperature $\left(t_{a s}\right)$, daily minimum near-surface temperature $\left(t_{\min }\right)$, daily maximum near-surface temperature $\left(t_{\max }\right)$ and precipitation (pre) (see Table 1).

The study region covers Lower Franconia $\left(8-12{ }^{\circ} \mathrm{C}\right.$ E, $\left.49-50.75{ }^{\circ} \mathrm{C} \mathrm{N}\right)$, a designated hot spot of climate change [9]. In the following, rain is used as a synonym for precipitation, although hail, snow, etc., are also included in precipitation. There exist much higher thresholds for defining intense precipitation, but as heavy precipitation is commonly limited to small spatial entities and all data used here as means over grid cells of about $150 \mathrm{~km}^{2}$, higher extremes are hardly discernible.

Table 1. Climate indices used.

\begin{tabular}{ll}
\hline Index & Definition \\
\hline Number of frost days & $t_{\min } \leq 0{ }^{\circ} \mathrm{C}$ \\
Number of hot days & $t_{\max } \geq 30{ }^{\circ} \mathrm{C}$ \\
Number of dry days & pre $\leq 1 \mathrm{~mm}$ \\
Number of intense precipitation days & pre $\geq 10 \mathrm{~mm}$ \\
\hline
\end{tabular}

\subsection{Expert Interviews with EMAS-Registered Companies}

A distinctive element of our approach is the use of the Grounded Theory (GT) methodology according to [53] (see Figure 2), which promises a more intensive and substantial abstraction of theories from empirical data due to its detailed and analytical procedure. The conducting phase is characterized by the fact that it extends into the analyzing phase, where changes and modifications of the guideline, samples, etc., are also made. Thus, writing and analysis take place immediately after an interview is conducted and may influence further sampling (theoretical sampling). Grounded Theory is an approach which makes the researcher sensitive to create an awareness of multiple data meanings to conceptualize and discover theory from them [53]. The characteristic of the iterative process involving open, axial, and selective coding is that these individual steps intertwine, weave the information together, and influence the decisions regarding which data will be collected next. Furthermore, according to [54], theoretical sampling includes circularity of individual steps of analysis, data collection and theorizing. There is an interdependence between the different stages that is similar to the hermeneutic circle and also provides a high level of open-mindedness throughout the research process. The so-called theoretical saturation is reached exactly when no more codes, categories or theories can be derived from the data. 


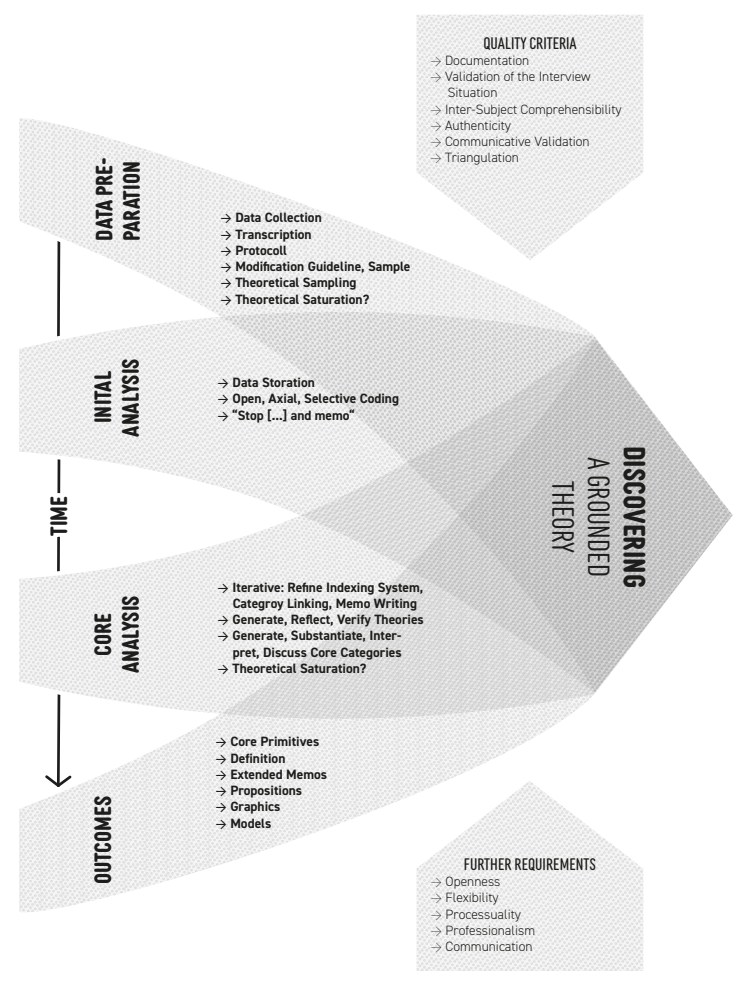

Figure 2. Process of discovering a Grounded Theory. Own diagram (based on the literature according to Böhm [55], Glaser and Strauss [53], Mayring [56] and Pidgeon [57]).

\subsection{Theoretical Sampling}

Generally, theoretical sampling ensures that the researcher is open-minded regarding the research subject. Indeed, the researcher decides which, how, and where further data will subsequently be collected on the basis of the interviewees engagement with available data $[53,58]$. To conduct the interviews, a semi-structured guideline was developed which, while outlining a set of questions and order [47], left a large open space and therefore functioned rather as a conversation guide. The included questions were designed to be explorative and open, in order to encourage the interviewees to reveal specific experiences or knowledge; see Appendix B. In the beginning as part of an exploratory phase two, EMAS experts were interviewed; see Table 2. The renowned environmental management Eco-Management and Audit Scheme (EMAS) certification is considered ambitious and is recommended by governmental institutions. This approach serves to gain an overview of the procedure for analyzing specific organizational levels and related identification of barriers and promoters with respect to climate mitigation and adaptation. Furthermore, we aim to obtain valid information on the scope and mentality regarding climate adaptation based on self-assessment and external assessment. Additionally, 11 interviews were conducted with companies which already were EMAS-certified; see Table 2. As four interviews were conducted with two or more people, we interviewed a sample of 18 people about their opinions and experiences on climate adaptation. Among them, eight persons have a management position (e.g., managing director, plant manager), six have the function of sustainability officer or environmental officer and two others are area-specific employees (e.g., laboratory staff). Further, two work as consultants, which also cooperates with federal initiatives. All 13 interviews were conducted within a period of ten weeks (May to July 2021) and by using a video conferencing tool. With the respondents' consent, the interviews were recorded and subsequently transcribed in accordance to standard orthography. 
Table 2. Demographic data. In four companies, two or more people were interviewed.

\begin{tabular}{lll}
\hline Feature & Attribute & Value \\
\hline \multirow{3}{*}{ General data interviewees } & Number of companies & 13 \\
& Men & 15 \\
& Woman & 3 \\
\hline \multirow{3}{*}{ Function } & Sustainability Manager & 5 \\
& CEO & 8 \\
& Consultant & 2 \\
Category & other & 3 \\
& Manufacturing Company & 9 \\
\multirow{2}{*}{ Company size } & Service Company & 4 \\
\hline \multirow{2}{*}{ Business age } & Microenterprise & 2 \\
& Small & 3 \\
& Mid-size & 2 \\
\hline \multirow{2}{*}{ Year of 1st EMAS } & Big & 7 \\
\hline
\end{tabular}

\section{Results}

\subsection{The Lower Franconia Region from a Climate Perspective}

\subsubsection{Temperature and Related Indices}

For all temperature-related indices, a clear warming trend is evident until the end of the 21st century. In Figure 3, this is exemplified by the number of hot days (see Table 1). The spatial pattern exhibits the highest number of hit days in the Lower Main region (which is part of the Rhine Rift Valley) and the lowest number in the north-eastern low mountain ranges (Rhön, extensions of Thuringian Forest). The deep valley of the river Main is warmer than its surroundings.

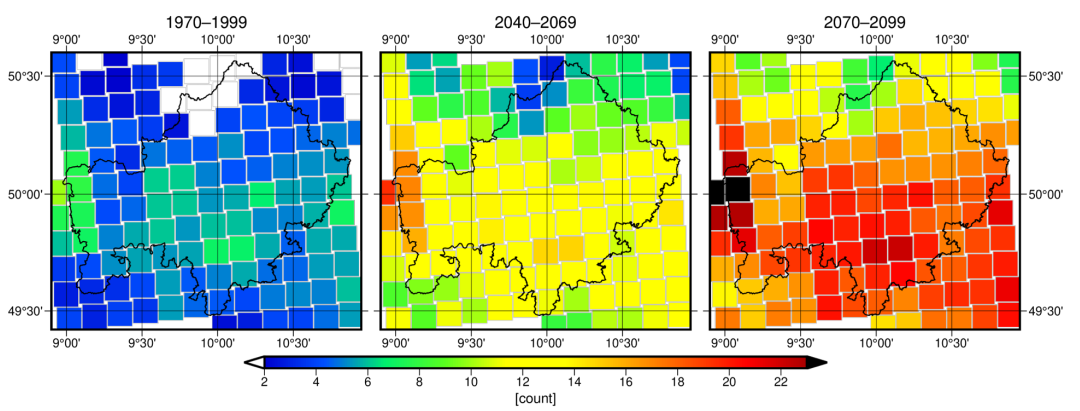

Figure 3. Number of hot days simulated for the end of the 20th, the middle of the 21st and the end of the 21 st century.

The regional mean of annual frost days (not shown) declines from 77.2 (regional minimum 49.8 to regional maximum 126.0) under present-day conditions over 47.5 (26.7-87.5) towards the mid-twenty-first-century to 21.1 (7.7-52.8) until 2100. Monthly values reflect this, with the number of frost free months increasing from 3 (June to August) over 4 (June to September) to 5 (May to September) over the same time period. The (monthly and) annual mean temperature rise $\left(8.8^{\circ} \mathrm{C}\left(6.2-10.7{ }^{\circ} \mathrm{C}\right) \rightarrow 10.6{ }^{\circ} \mathrm{C}\left(8.1-12.4^{\circ} \mathrm{C}\right) \rightarrow 12.2^{\circ} \mathrm{C}\left(9.6-14.0^{\circ} \mathrm{C}\right)\right.$, not shown) is also mirrored in the increasing number of hot days projected (4.8 (0.3-16.1) $\rightarrow 11.3$ (1.6-27.5) $\rightarrow 17.4$ (4.8-33.2), see Figure 3) and the number of months affected (May 
to September $\rightarrow$ April to October). Most hot days are projected for July $(2.3(0.2-7.1) \rightarrow 4.1$ $(0.6-9.3) \rightarrow 6.1(1.9-11.4)$.

At first glance, these hot day numbers might be low, but one has to keep in mind that long-term means of a whole region in respect to a grid box of about $150 \mathrm{~km}^{2}$ are considered. When considering single years or lower spatial unities, e.g., urban areas, heat extremes can be much higher. The highest monthly (annual) values projected are 21 (40), resp. 20 (54) and resp. 28 (60) for each period (which are still grid cell values, i.e., averages over about $150 \mathrm{~km}^{2}$ ).

\subsubsection{Precipitation and Related Indices}

In contrast to temperature, projections for annual precipitation and derived indices do not exhibit clear trends, except for a small increase in annual precipitation sum (regional mean $944.2 \mathrm{~mm} \rightarrow 971.4 \mathrm{~mm} \rightarrow 978.7 \mathrm{~mm}$ ) and number of intense rainfall days $(24.6 \rightarrow$ $26.3 \rightarrow 26.9)$ that is visible. Several months, particularly in spring and autumn, are not characterized by coherent trends. In detail, monthly precipitation sums increase in January and December, while they decrease in July and October. Moreover, displayed in Figure 4, the number of heavy rainfall days is projected to rise in January $(2.0(0.2-6.2) \rightarrow 2.5(0.3-6.9)$ $\rightarrow 3.1(0.4-8.1))$ and drop in July $(2.7(1.0-6.1) \rightarrow 2.5(0.9-5.3) \rightarrow 2.1(0.7-4.9))$.
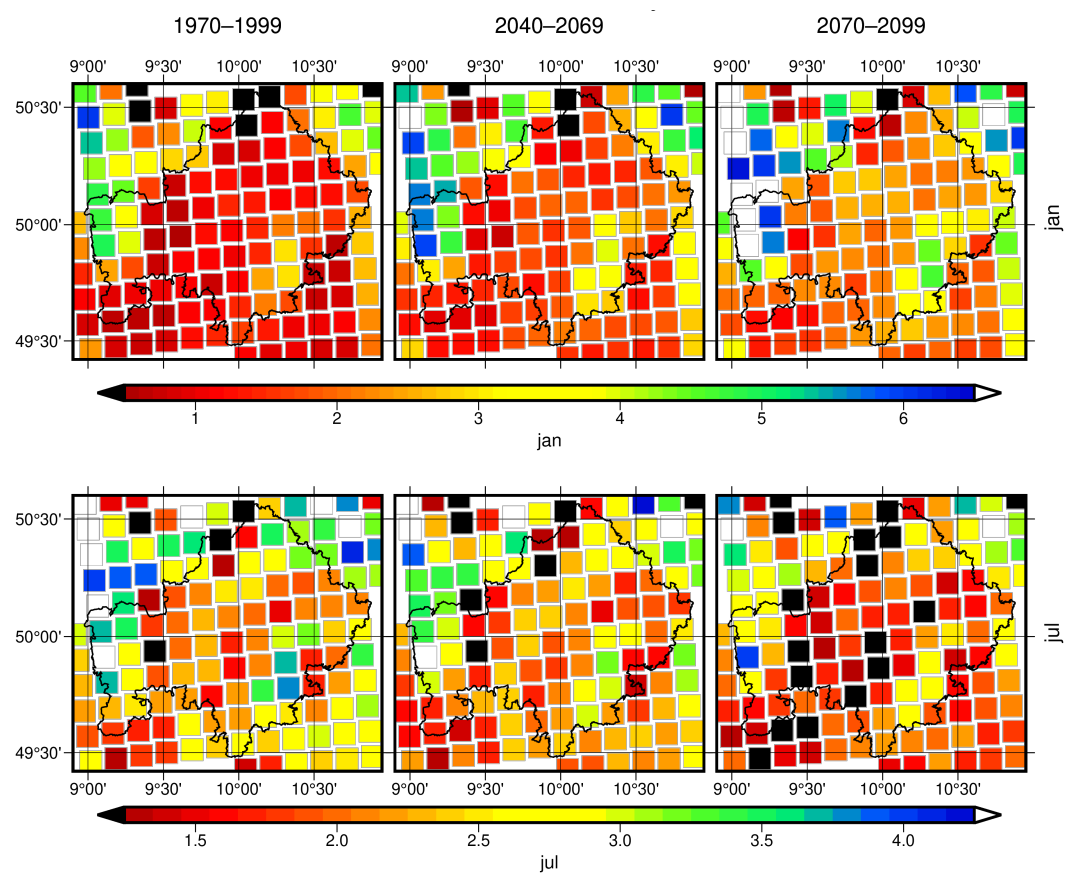

Figure 4. Number of intense precipitation days in January (top panels) and July (bottom panels) projected for the end of the 20th, the middle of the 21st and the end of the 21st century.

The direction of changes in dry day frequency is also not clear when considering the entire year (mean 213.4 $\rightarrow 215.1 \rightarrow 214.7$ ), spring or autumn. However, a negative trend in winter (December to February, $51.9(41.1-66.7) \rightarrow 47.8$ (37.1-63.3) $\rightarrow 44.5$ (33.3-59.2)) contrasts with a positive trend in summer (June to August, $52.2(40.0-68.9) \rightarrow 54.2(42.4-69.2)$ $\rightarrow 56.4(44.2-70.4))$, as can be seen in Figure 5 . 

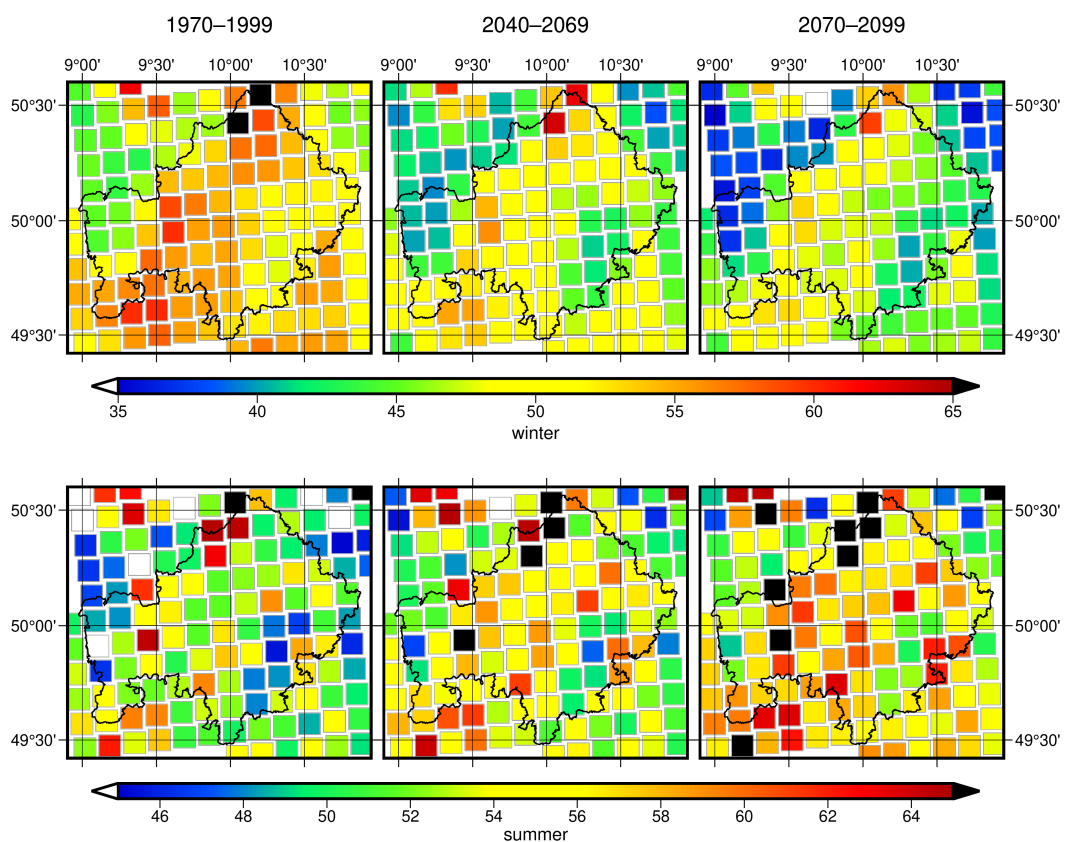

Figure 5. Number of dry days in winter (top panels) and summer (bottom panels) projected for the end of the 20th, the middle of the 21st and the end of the 21st century.

In summary, temperatures are projected to rise with cold extremes becoming less and hot extremes becoming more frequent. Winters are projected to face more and summers less precipitation, which is also reflected on the extremes. The combination of higher temperatures and less rainfall during the summer season points to an enhanced problem of water stress during that time of the year that has the largest water demand. Recent years have foreshadowed this tendency. The following sections illustrate the extent to which the companies studied already include climate change in their strategy development and adapting to it.

\subsection{Climate Adaptation in EMAS-Registered Companies}

Following the principles of GT, the expert interviews were analyzed within an iterative coding process. The methodology thrives on the creativity and theoretical linkage of facts that are paraphrased by means of concepts or so-called in vivo codes. The challenge for researchers is the lack of standardization and multiple ways of interpreting the different coding schemes as well as the need to proceed in a way that allows others to comprehend the system. To ensure that the findings become intersubjectively comprehensible, a coding example based on an anonymized interview passage is shown in the Appendix A to explain the coding phases. During the selective coding, we identified three core categories, which interlink all interviews and are based on three derived theories:

1. Economic Efficiency: The most important purpose is economic efficiency, which all climate change-related measures are subjected to.

2. Dynamic Organizational Environment: The impact of climate change varies among the companies studied, and simultaneously, the organizational context (e.g., sector, resources, product, organizational culture, etc.) determines the extent of exposure, vulnerability and adaptation to climate change.

3. Change Management: Climate adaptation usually takes place in an implicit manner within climate mitigation measures, partly due to regulations or incentives (e.g., funding for photovoltaic installations or subsidies for the EMAS-certification).

These theories and categories constitute the core of our findings and represent a central phenomenon of the empirical examination. Figure 6 shows the derived conceptual diagram, which illustrates the core categories and associated subcategories. All core categories and 
related subcategories contain further dimensions which will be used to explain the specific features, interrelations and differences. Subsequently, the results will be explained in Section 5 which is dedicated to answering the research questions.

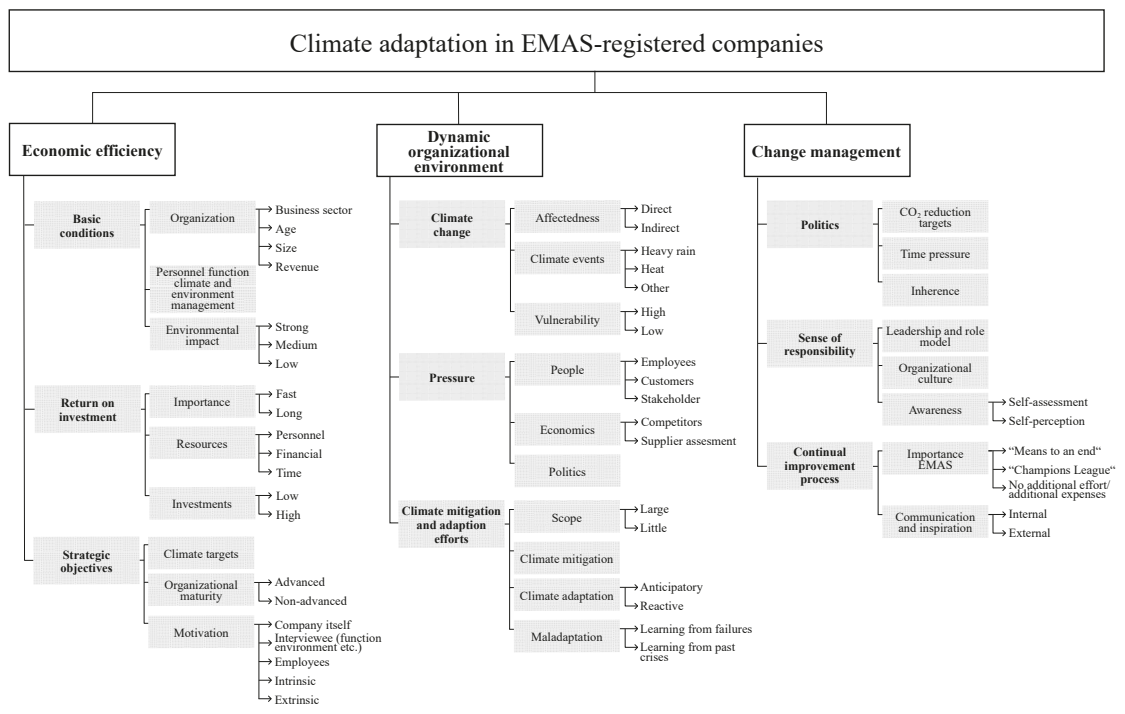

Figure 6. Identified Core Categories, subcategories and related dimensions. Depending on the core categories and related subcategories, further levels open up, which are used to explain the specific features and differences.

\subsection{Core Category: Economic Efficiency}

The quest for economic efficiency was expressed in every interview, regardless of whether the company was a global player or a small service company with church funding. The identified core category has a very strong foundation, as all interviewees mentioned a lot of relevant information on the current framework and promoters or barriers in dealing with climate change, which are closely interlinked. According to the European Union definition [59], seven of the 13 studied companies are large enterprises (250 or more people employed), including four companies with sites in other countries, e.g., South Africa and India. The other six companies are classified as SMEs. Several companies are operating in the market for decades, with an average of 87 years $\left(\mathrm{s}^{2}=42\right)$ overall. Among the companies surveyed, four were subsumed under the "service provider" category; these tend to have a normal carbon footprint, i.e., they do not emit exceptionally large amounts of greenhouse gases. Five manufacturing companies produce greenhouse gases, but within normal limits, i.e., they do not release large amounts of acids and gases. In contrast, there are four manufacturing companies that release very high amounts of emissions, e.g., through energy-intensive processes, such as in the production of steel products. Generally, the negative ecological impact correlates with the extent of political barriers and reduction targets on the companies and their climate-related measures. Furthermore, it is evident from four companies that organizational conditions, i.e., external requirements by authorities or other ordinances, are partly responsible for these companies not implementing measures such as photovoltaics or reducing plastic waste. One company is subject to monument protection and could not install a photovoltaic system $\left(I_{7}\right)$, while four other companies reported hygiene standards inducing high water consumption and plastic waste $\left(I_{3}, I_{8}, I_{9}\right)$. In the following, individual interview statements of the interviewees are given a short reference equivalent to the coding $I_{x}$ with $I$ as interview and $x$ as number of interviews from 1 to 13 , e.g., $I_{7}=$ Interview 7 ).

The striving for profitability and efficiency of measures in which personnel, financial and time resources have been invested is at the forefront of all actions and decisions of all companies surveyed. Here, one automotive supplier and global player $\left(I_{3}\right)$ summarizes: "if you are quite honest, the industry is driven very strongly by the economic factors. 
Anything which is not dictated by the legislator or which does not have an economic benefit in any form is very difficult to implement". Thus, the companies studied can be divided into three categories. Companies, where resources or investments are rather scarce and which only introduce measures with a short return on investment (ROI); one interviewee $\left(I_{4}\right)$ emphasizes: "we are not driven by environmental policy [reasons] or environmental responsibility". Further, some companies are in a state of change, where longer ROIs increasingly are accepted: "in the past, nothing was done that did not have an ROI of less than two years" $\left(I_{3}\right)$. The interviewee refers to a change in corporate philosophy as one reason for this, and he mentions that measures in the energy sector often have an amortization period of 5 to 15 years. Finally, there are companies, which genuinely implement measures with a longer ROI and simultaneously accept an economic risk by prioritizing energy and environmental aspects. In this regard, one interviewee $\left(I_{13}\right)$ reports on the impact when the company shifted to more sustainability and carbon-neutral operations within one year. For this purpose, investments in the tens of millions have been made, and measures such as photovoltaic parks have been established, which have a higher amortization period of 5 to 7 years. The related sustainability manager states that a significant competitive advantage has arisen in the meantime, due to lower $\mathrm{CO}_{2}$ costs and independence from the development of electricity prices. Irrespective of the fact that internal rethinking processes are increasingly taking place with the changes in the external environment and growing demands from stakeholders, the organizational adaptation capacity and the management level in particular are responsible for the importance attached to ROI. One large company $\left(I_{12}\right)$ states that investments always must be represented.

Climate mitigation and adaptation are also influenced by the company's size and related revenue. In particular, larger manufacturing companies (all global players) with a high environmental impact, i.e., high energy and resource consumption, had extensive resources to meet the increasing environmental requirements. Two interviewees from automotive companies, for example, mentioned that the company's environmental management department at the respective site has many personnel resources (16 employees $\left(I_{11}\right)$ and 14 employees $\left(I_{12}\right)$ to deal with climate-related issues such as EMAS certifications and legal requirements (see Supply Chain Act, Federal Climate Protection Act). In contrast, a supplier $\left(I_{3}\right)$ refers to personnel inhibitors and a lack of "manpower" and mentions that money is not a problem, but time resources are limited. All other companies reported the climate-related tasks, e.g., providing the database required for the EMAS environmental report, as additional tasks.

Almost half of the companies reported that the EMAS certification only caused a considerable workload at the beginning and now, after years of experiences, it comes "on top" through established structures and meticulous documentation processes. Nevertheless, they concede the certification as being demanding due to providing extra data and explanations for climate indicators and planned strategies. As part of the certification process, the companies set annual objectives and performance indicators. In case of non-achievement, the processes are redefined accordingly. Furthermore, the respondents were asked to provide a brief self-assessment based on school grades (6-point scale ranging from 1, excellent to 6 , insufficient) to rate the current state of their climate adaptation strategies including appropriate explanation of reasons (see Appendix B). Here, they refer that the companies themselves set very high climate targets and $\mathrm{CO}_{2}$ limitations. In general, companies reflect on their activities and targets in comparison with other similar companies and note that they act in a climate-friendly manner better than the general average. Averaging a grade of two minus, the companies' self-assessment also reflects this extra engagement. While none of the companies surveyed is a carbon-neutral company, three companies are moving toward this target. To become a zero-carbon company, two companies reorganize processes to rise the use of regenerative energies and to cooperate with renaturation projects. At the same time, they recognize this target as being still far away. One manufacturing company $\left(I_{13}\right)$ is bringing forward the target to become carbon-neutral within one year. For this purpose, it invests millions of euros in photovoltaic systems and measures such as 
an internal sustainability academy and also provides funds for measures that take long to amortize. For almost all of the companies, the climate-related organizational change process first ran more in the background and established itself firmly in the context of the EMAS audit. In general, the advanced organizational maturity of the companies influences to what extent they operate in a more climate-friendly way than the average, which means that they are prepared to put in the time, investments and effort required. The level of maturity correlates with individual knowledge, experience and the volition to pursue a continuous exchange of ideas at the macro level. Simultaneously, all companies invest effort in further topic-related networking and in gathering information from consultants or scientific institutions.

\subsection{Core Category: Dynamic Organizational Environment}

All interviewees consider each of their activities within the context of a dynamic economy and mention not only regulations or pressure from politicians or stakeholders, for example, but also consider consumers themselves. One energy supplier $\left(I_{9}\right)$ notes the interplay between climate change and electrification, e.g., rising e-mobility and increasing digitization are leading to rising electricity consumption. The water supplier $\left(I_{10}\right)$ also does not want to mention a "water defense struggle and war", but discusses the risk of distribution difficulties. The interviewees clearly emphasize that the actions taken so far with regard to dealing with climate change were not initiated due to economic damage, which can be traced back to specific climate events, for example. In fact, with the exception of three companies, the companies studied reported neither direct climate damage nor any monetary valuation of climate change and its impacts. Two of the affected companies experienced intense rain, resulting in damage amounting to millions of euros. Further extent of damage was reported at global sites, e.g., in India, where flood damage occurred in the production plant. A supplier also said that production at other sites had already been shut down as a result of water shortages. In the investigated region, the average temperature is rising and causes water evaporation and a decreasing groundwater level. According to a utility, climate change has a negative impact on the region's water resources balance, as precipitation and consumer behavior negatively affect groundwater levels. The general redistribution increases social disproportionality, as consumption processes are unequal, but prices are equalized. Similarly, ecosystems in the forest and nearby river are changing, e.g., the increase in temperature leads to a higher growth of algae.

Generally, one expert $\left(I_{2}\right)$ observes that companies usually focus their considerations on their production plants only, while the topic of climate mitigation at a global level is still quite abstract to them. Besides an increase in average temperature, most of the interviewees recognize water shortages, a higher incidence of heat days and intense rains as core weather events. Furthermore, a general awareness of climate change is apparent among all respondents; one manager $\left(I_{5}\right)$ emphasizes that there are "no climate change deniers" within the company. However, most reported adaptation measures initially based on external pressure. As described previously, manufacturing companies, which have energy-and resource-intensive processed are particularly affected by climate change due to the rising cost of resources and, frequently, political targets for the reduction of greenhouse gas emissions [6]. However, external pressure from customers and dependent supply chains also creates a need for companies to take concrete actions. Generally, only a few companies justify the interventions in view of an intrinsic motivation or internal conviction to do more for climate.

The reasons for climate mitigation and adaptation can be traced back to indirect factors in most cases. Here, one crucial aspect is political pressure, as new regularities are continuously published, carbon taxes are imposed, and the price of energy is increasing. As one interviewee points out, this is related to the energy transformation in Germany, which he considers to be a direct result of climate change $\left(I_{10}\right)$. Additional pressure comes from consumers expecting companies not to be seen as "environmental sows" $\left(I_{3}\right)$ so that the companies positioning in this regard affects their purchase decisions. Further, the 
topic of supply chains is becoming increasingly important. Especially suppliers are under pressure, which occurs within the supplier assessments. The so-called "scope 3 emissions", for example, include the largest amount of produced emissions, which already begin in supply chains. Here, a trend is emerging whereby companies analyze and optimize not only their own processes and environmental impacts but also consider the supply chain and require adjustments. This extends to the point where suppliers are asked to comply and are excluded from the contract if further action is not apparent $\left(I_{13}\right)$. In addition, four interviewees pointed out that attitudes of employees and citizens have changed, too, making demands on climate-friendly business activities. Immediately with the first interviews, it became apparent that the term "climate adaptation" is not familiar in practice and therefore cannot be used to obtain information on the research subject. This fact is confirmed in all interviews. Indeed, the respondents tend to use terms such as "sustainability management" and "climate mitigation" and do not differentiate into a more specific "climate adaptation". Accordingly, a classification into climate mitigation and adaptation is carried out retrospectively; see Table 3. Thus, an overview of common measures is provided by categories. Here, it must be taken into account that the respondents may not have mentioned all the measures implemented and that some measures are certainly considered "self-evident" and therefore were not listed. In the case of three frontrunner companies with a "close-to-nature" philosophy, for example, certain measures have been taken for years and were not considered as part of their adaptation measures.

Table 3. Categorization of climate mitigation and adaptation.

\begin{tabular}{|c|c|c|}
\hline Approach & Category & Examples \\
\hline Mitigation & Buildings & $\begin{array}{l}\text { Rooftop greening, photovoltaic systems, new refrigeration } \\
\text { own plants, use of sustainable inventory }\end{array}$ \\
\hline Mitigation & Corporate responsibility & $\begin{array}{l}\text { Reforestation projects to compensate carbon dioxide, } \\
\text { carbon neutral company, bio-organic catering }\end{array}$ \\
\hline $\begin{array}{l}\text { Mitigation, } \\
\text { Adaptation }\end{array}$ & Renewable energies & Green power, regional biogas, photovoltaic installation \\
\hline $\begin{array}{l}\text { Mitigation, } \\
\text { Adaptation }\end{array}$ & Tools, Methods & $\begin{array}{l}\text { Life cycle assessment, EMAS, ISO 14001/9001 } \\
\text { sustainability road map }\end{array}$ \\
\hline Mitigation & Energy & $\begin{array}{l}\text { Use of renewable energies, lighting replacement, } \\
\text { automatic switch-off and regulation systems }\end{array}$ \\
\hline Adaptation & Cooling & $\begin{array}{l}\text { Thermal Insulation, Night ventilation, chilled ceilings, } \\
\text { air conditioning }\end{array}$ \\
\hline Adaptation & Working conditions & $\begin{array}{l}\text { Cost-free beverages, temperature-regulating workwear, } \\
\text { changes of working hours and breaks, homeoffice }\end{array}$ \\
\hline Adaptation & Technological features & $\begin{array}{l}\text { Water protection hose } \\
\text { electric vehicle fleet }\end{array}$ \\
\hline Adaptation & Incentives for employees & $\begin{array}{l}\text { Idea managing, vouchers, } \\
\text { contests, carbon tracking }\end{array}$ \\
\hline $\begin{array}{l}\text { Adaptation, } \\
\text { Mitigation }\end{array}$ & Training and education & $\begin{array}{l}\text { Working groups, organizational development, } \\
\text { workshops to low-carbon driving, videos and tutorials }\end{array}$ \\
\hline
\end{tabular}

Generally, various interviewees mentioned the importance of considering state-ofthe-art technologies when designing new buildings or halls, as well as the importance of digitalizing internal processes in general and using technological measures that can be used to monitor and regulate consumption. Moreover, the reciprocal effect of climate mitigation and adaptation becomes apparent, especially in the case of energy-related measures such as the use of renewable energies, installation of photovoltaic systems or general investments in modern, technological systems. These measures contribute to climate mitigation through energy efficiency and low emissions, as well as to adaptation 
to regulatory requirements. Conventional air conditioners represent another well-known example of the reciprocal effect as most air conditioning systems are used to adapt hot temperatures to cooler ones, but in doing so, they consume considerable amounts of energy and require climate-damaging refrigerants. The measures vary according to companies and whether climate change is directly affecting them.

\subsection{Core Category: Change Management}

So far, climate change is only one element of the dynamic organizational environment, which poses challenges and strict demands. Irrespective of initial resource input (especially financial and personnel resources), all companies appreciate the EMAS-related associated transparency and control authority for their continuous guided development and change management. Generally, any kind of regularity requirements prove to be key factors in introducing climate-relevant measures. This political driver emerges particularly in manufacturing companies. In response to questions about political requirements, the primary topics were energy taxes, the European Emission Protection Act and supply chain laws $\left(I_{12}\right)$. It became apparent that EMAS certification sometimes served as an intervention to provide companies with legal compliance and legal certainty. With regard to current political conditions, the interviewees criticized three aspects in particular. First, the rapidity of new regulations, second, the multitude of regulations and their unsuitability for practical application, and third, the lack of consistency among the executive authorities. One automotive supplier, for example, is confronted with a large number of regulations and reports. Even internal specialists wonder to what extent these are practicable at all. Generally, all respondents rated the political regulations as considerably critical and influential, compared to the specific climate incidents themselves.

The interviews with the EMAS experts indicate that no general statements can be made regarding the extent to which companies are affected, nor their level of knowledge and strategies. Instead, we can see that despite the different initial impetus for climate adaptation and the high priority given to economic efficiency, the companies are taking their responsibilities seriously and reflect both their processes and their products.

With regard to the Continuous Improvement Process (CIP) described as part of EMAS, it becomes clear that the companies are not only encouraged to continue developing themselves and their activities as a result of the certification. Moreover, it is driven by a sense of responsibility towards environmental issues and an interest in taking responsibility regarding their impact on the climate. One consultant reports that within the last ten years, besides many service providers, public institutions have registered "that they also have an environmental footprint" $\left(I_{2}\right)$. Further, one EMAS-expert reports that especially larger companies, such as automotive suppliers, which operate globally, have great resources for adapting to external conditions. However, they have a different motivation for climate mitigation than smaller companies. He observes a clear difference between owner-managed medium-sized companies, "which have a generational perspective", and those with employed managers, e.g., DAX-listed companies. Despite the potential availability of resources, these companies focus on meeting their target systems, whereby climate mitigation may sometimes take a back seat $\left(I_{1}\right)$. The respondents' personal attitudes in their climate-related functions were likewise highly engaged toward climate and sustainability. Almost all of them have been dealing with the topic of climate and sustainability for several years. It also became obvious that companies with managers who carried a high level of responsibility for climate and who communicated their commitment internally, appeared to be more advanced in climate-related change processes. Part of this is tied to greater executive leverage to allocate resources and involve external support. It is also closely related to the corporate culture and the underlying values, which differ according to the product or service of the company and the so-called "founding fathers" $\left(I_{5}\right)$. Here it goes from very close to nature companies, through producing companies, which have a distinctive consciousness and volition to arrange the enterprise sustainable and environmental friendly, to companies which only 
meet the (EMAS) minimum standards. In four companies, the topic of sustainability is anchored in the company's history and is promoted by management.

All larger companies have internal working groups or external consultants to integrate climate considerations into their product development. Approximately one-half of the respondents attach great importance to internal working groups dealing with climate adaptation, to address external requirements and to initiate discussions on dealing with new challenges. Simultaneously, especially advanced companies show that knowledge can be accumulated with such an approach, which becomes anchored strategically and therefore fosters organizational learning. At least four companies showed that these working groups were composed inter-disciplinarily and represented all hierarchical levelsfrom cleaners to managers. Here, it was emphasized that each of them has an equal voice: "the cleaning specialist has a voice there, on an equal level with other leader" $\left(I_{3}\right)$. All companies exchange information with external consultants or experts as part of the EMAS certification process. At the same time, this creates low-threshold access to other companies, as one interviewed managing director recounts in a personal conversation (post-interview observation, date) referring to the benefits of the "EMAS family".

Finally, the interviews indicate that not only companies need to change their awareness but also that the political side as well as the consumer side are involved in the change process and that, as mentioned in the introduction to this contribution, considerable changes in behavioral and consumption patterns are required. Here, one interviewee states: "People want $\mathrm{CO}_{2}$ neutrality but they do not want changes in their individual environment, it's a societal problem".

Regardless of the initial motivation to implement EMAS, all respondents assess the benefits of the certification as very positive, especially regarding resources (personnel and time). Besides those companies which wanted to enhance external visibility of their climate-friendly measures or which wanted to ensure process and legal compliance, nearly all companies mention the external control as a significant benefit for a continuous improvement process. Within the "EMAS family" $\left(I_{10}\right)$, a respondent explains, the knowledge and experience of other companies will be transferred by the auditors into their own companies. This creates an implicit, interdisciplinary exchange at a high level of innovation, as all companies develop further within the framework of CIP.

\section{Discussion}

\subsection{Climate Change and Climate Adaptation in the Lower Franconia Region}

This study results from the assumption that for organizations beyond the primary sector (e.g., agriculture), the topic of global climate change and climate adaptation is frequently complex and abstract. To bridge this natural distance, the synthesis of different, scientific disciplines is used. Therefore, regional climate data and projections from the field of natural sciences were contrasted with the subjective assessment of (affected) economic actors, as well as the barriers and promoters of organizational learning processes were analyzed. This relates to the assumption that organizational learning is a key element for an organization to be efficient under economically and climatically dynamic and volatile conditions; see $[29,32,37]$. By linking climate adaptation and organizational learning, we aim to demonstrate that successful climate adaptation must be handled strategically. It implies an approach according to fertile learning processes by analyzing organizational processes, values and cultures as well as the capabilities and needs of the members comprehensively in taking action (see [37]). An adaptation requires changing behaviors and attitudes; at the same time, organizational learning derives from experience, from mistakes that are corrected and new actions that are derived from these mistakes; see [33,57]. Climate adaptation and organizational learning undergo an interaction when learning-promoting elements are given.

Thus, for assessing the adaptation needs for economic actors, climate projections of the regional climate model REMO are analyzed for the region of Lower Franconia. In the course of the 21st century, rising temperatures are accompanied by a lower frequency of 
cold and a higher frequency of warm extremes. Whilst precipitation sums and the number of heavy rain days are projected to slightly increase in annual terms, a seasonal contrast of more winter and less summer precipitation can be detected. Altogether, warmer and dryer summers (and milder, wetter winters) are projected. Materials as well as employees may suffer from these hot and dry summer conditions, raising the need for adaptation measurements particularly in the field of temperature regulation. The climate model analysis for the region illustrates that climate change is already noticeable and temperatures are projected to increase further, thus impacting companies beyond the primary sector in the future. This finding contrasts with the current extent of climate adaptation, since only five companies are affected by climate change directly.

The most reported climate adaptation measures lie in the field of compliance regarding regularities for climate mitigation, and there is no trend of a responsive climate adaptation; see [13]. Hence, energy use and production of climate-damaging emissions represent the biggest issues. In general, the external perspective provided by the EMAS-experts confirms that many companies are rethinking their strategies and raising their awareness. A general consensus prevails that a "business as usual" attitude is neither expedient nor sustainable. All companies interviewed already have set high standards (in comparison to the average companies) for climate mitigation and adaptation within the EMAS-framework and usually realize measures without considering them to be specific climate adaptation or "special measures". This is even more noticeable in companies where the issue of climate and environment is already integrated into the corporate culture, companies with a high sense of responsibility (see [31]) and companies which motivate their employees to act in a climate-friendly and responsible manner by using corresponding communication and incentives systems. These findings are to be verified by the complement regional study, which provides a reliable representation of the population within the investigated region. As an effective and strategic adaptation to climate change not only requires new ways of thinking but also learning processes, the discussion and answer of our second research question is of equal importance regarding further research projects. Regarding the finding that the interviewed companies frequently addressed the issue of climate change within the framework of EMAS-certification, more promoters of climate adaptation and organizational learning were identified than barriers to them.

\subsection{Simultaneous Barriers and Promoters of Organizational Learning}

It becomes apparent that economic efficiency simultaneously promotes and inhibits climate adaptation. Generally, "there is no magical bullet" [37], real progress in the face of climate adaptation is related to modified organisational processes, employee training and familiarization with new tasks and process structures, which necessitate financial and human resources; see $[33,35,36]$. This starts technically by investing in climate-friendly building equipment, specialized installations such as photovoltaic systems, biogas plants or energy-saving refrigeration systems. From a conceptual point of view, it involves consulting (external) expertise and further training programs. The new knowledge acquired in this manner should be communicated internally and implemented into practice. In some companies, this is done, for example, through video messages from management or executives, information videos, and internal, interdisciplinary working groups. Such formats support organizational learning by enabling externalized knowledge, e.g., provided by external experts, to be picked up and discussed internally and subsequently promoting the adaptation of previous operational processes or corporate structures; see [37]. Thus, subject-specific working groups enable external changes or requirements to be prepared, piloted and discussed in a manner that suits both the company and the affected departments. Here, potential malfunctions and further needs can be identified and optimized. When these kind of changes are strategically successful and further instruct the actions and decisions of the future, it is an indicator that organizational learning has taken place. Subsequently, learning will be established in concrete theories of action, e.g., as Argyris and 
Schön [32] state, as well as in an organizations' values and norms, i.e., in the underlying organizational culture; see Schein [38].

Closely linked to the issue of economic efficiency, organizational conditions prove to be both an obstacle and a promoter. According to the organizational resources, aspects like resources, regularities and environmental impact are weighted differently and climate adaptation is carried out implicitly or explicitly at different points. However, the companies interviewed also show that ideas and measures are being developed far beyond the current external requirements to also meet the requirements of employees and customers. This is done with a view to a shift in thinking and awareness about responsibility for climate and environment. Accordingly, the companies take responsibility for the subject of learning (see [31]), i.e., climate change and its adaptation. Smaller companies with fewer resources, are not behind the larger companies by any means, as the interviews showed. In addition to organizational "technical" framework conditions, "human" framework conditions are also very crucial to the extent of organizational learning within climate adaptation. When managers or those in the specific function (e.g., environmental and sustainability managers) had a progressive, reflective attitude and high levels of experience with respect to climate change, more profound, authentic adaptation measures were implemented in the respective company, which were then partially linked to the close-to-nature corporate philosophy. These findings are consistent with the studies reviewed regarding barriers and promoters of climate adaptation by managers [21,22,24,29].

As mentioned, it appears that larger companies foster organizational learning by having dedicated, well-staffed departments that potentially represent a productive learning environment for employees and also provide a space for mistakes or misguided decisions to be made. Opportunities for in-house training of employees, for example, by means of a sustainability academy, internal working groups and competitions, to access organizational members' knowledge and experience, are generally promoted.

The pressure and the challenging regulations regarding climate change from politics were discussed in all of the interviews. In particular, among companies that cause a lot of emissions, this pressure serves as a promoter for climate adaptation, since dealing with the issue of climate change and the requirements becomes unavoidable, and resources, therefore, have to be deployed faster. Thereby, learning effects can occur when initially imposed adaptation measures are effective and even have positive effects for the company. This might motivate companies to engage more deeply with the issue and to develop measures themselves voluntarily. On the other hand, one aspect related to policy could have a rather negative effect on learning processes. Several times, the participants referred to inherence, lack of transparency and lack of practical suitability of regulations. These experiences can result in incomprehension, resentment and blockages among companies, which in turn leads to negative connotations of climate change and a tendency to "do what is necessary". In addition, political restrictions have also torpedoed approaches to adaptation (e.g., no photovoltaic systems due to the protection of historical monuments) and this, in turn, has affected companies' motivation for greater commitment in general.

\subsection{Promoters of Organizational Learning}

As the related work illustrates, management plays a key role in promoting organizational learning [18,24,41]. Management is responsible for channeling external requirements, identifying the organization's demand for change and encouraging it internally, e.g., with external consultants, new operating instructions or the composition of working groups. Generally crucial for organizational learning is the way of dealing with errors, e.g., that a constructive error management culture be fostered, and flat, profound communication systems exist through which management and employees can communicate needs, change requirements, as well as error and learning experiences. Some companies maintain permanent functional email addresses in addition to personnel functions.

The EMAS certification resulted in established processes and a collective development process, which encourages teamwork to develop individual responses and to define 
strategies. In terms of the dialogical nature of learning [60], the EMAS certification process indicates a continuous and profound engagement of companies with climate adaptation as an object of learning. In principle, a lot of knowledge is built up in the context of EMAS certification, "mastery knowledge" $\left(I_{1}\right)$, which also makes the companies "crisis-proof" beyond the climate change issue, as the companies learn to deal with their opportunities and risks and become motivated to examine their own structures and processes deeply.

Networking and exchanges between research institutions and companies in the same or similar sectors also motivate companies to take more action with regard to the environment to foster learning and knowledge transfer. In this way, mutual expectations may be communicated, expertise may be obtained and consciousness may be raised. The internal communication on the subject is also very important and a major driver of organizational learning.

In addition to exchanges, awareness and sensitization also take place in the collective. Especially advanced companies award prizes as incentives for innovative ideas regarding climate change and sustainability. Some examples are $\mathrm{CO}_{2}$ tracking systems that can be used in the private sector and $\mathrm{CO}_{2}$ compensation certificates that can be purchased for traveling to seminars by public transport.

Generally, organizational learning is fostered when all organizational members participate in change and development processes and when any learning experiences are accumulated, i.e., communicated and reflected in an active manner. Apart from certain examples of specific maladaptations, further information on the topic of handling maladaptations is lacking. More detailed findings could be an indicator how companies deal with and communicate maladaptive processes or misguided processes internally. Summarizing, to adapt operating and organizational processes strategically and effectively, employees or functions affected have to identify with any kind of changes in the external environment and related internal working processes. As Argyris and Schön [32] stated in their theory of organizational learning, there is always a divergence between the espoused theory and the theory-in-use. Regarding this, implicit knowledge is the most valuable knowledge of an organization and is accordingly adapted by the individuals to the changed processes.

Further, a set of rules for communication and interaction, as well as trust between the employees and management are important for organizational learning; see [21,35,37,60]. So far, climate change is only one element of the dynamic organizational environment, which poses challenges and strict demands. Therefore, organizational learning occurs neither less nor more than during any other external crisis, such as the COVID-19 pandemic.

\section{Conclusions and Further Research}

In conclusion, we only identify elements of organizational learning. To analyze learning processes over time and in the long run, we have to know more about the objectives, structures and error management cultures of the companies studied. In our contribution, we used indicators such as the annual improvement process through EMAS to assess whether companies change and adapt their climate-relevant processes only during certification, or whether they set their own objectives throughout the year and modify processes and behavior patterns and communicate them internally. Here, the examined companies show a high commitment to work on the topic in a strategic way and to collaborate with scientific institutions by investing personnel and time resources; for example, a total of eight executives were interviewed, in some cases up to four interview partners from one company at the same time.

Our findings confirm that the ecological and economic environment for companies is changing rapidly and extensively, and thus, it is necessary to implement suitable strategies and in some cases to realign organizational frameworks substantially. Although the industrial sector is vulnerable to climate events due to its high energy and resource consumption and interconnected supply chains, the indirect impacts of climate change (regularities, rising energy prices and taxes, supply chain assessment) have mostly been addressed so far. 
We consider that an effective climate adaptation is related to actual and region-specific data as the used climate model REMO. This is due to the fact that companies are mainly economically driven and usually do not consider adaptation strategies until a concrete damage case occurs. As science is a key factor for the further development of a society and economy, further research projects should address interdisciplinary approaches, the local focus of climate adaptation and the claim of actuality due to the continual development of external environment. Moreover, further research is required to examine how companies deal with errors and crises related to climate change. As in this study only the level of "knowledge-learning" was examined, further content-related aspects have to be investigated, regarding in-company education and training as a medium for creating learning environments and setting the course to establish and maintain organizational learning processes.

Author Contributions: Conceptualization, S.F.; Investigation, S.F.; Methodology, S.F.; Formal analysis, S.F.; Writing—original draft, S.F.; Visualization, S.F.; Writing—original draft, L.K.; Formal analysis, L.K.; Visualization, L.K.; Funding acquisition, H.P.; Supervision, H.P.; Writing-review and editing, H.P., Project administration, H.P.; Supervision, M.G.; Writing—review and editing, M.G.; Funding acquisition, J.S.; Supervision, J.S.; Writing—review and editing, J.S.; Project administration, J.S. All authors have read and agreed to the published version of the manuscript.

Funding: The authors gratefully thank the German Federal Ministry of Environment, Nature Conversion and Nuclear Savety for supporting the Projekt MainKlimaPLUS (Bundesministerium für Umwelt, Naturschutz und nukleare Sicherheit, Grant no. 67DAS216). Furthermore we acknowledge the REMO modeling group as well as the EURO-CORDEX project and the Earth System Grid Federation (ESGF) for producing and making available the REMO and all other EURO-CORDEX model data. Furthermore, we thank the MPI-ESM modeling group as well as the U.S. Department of Energy's Program for Climate Model Diagnosis and Intercomparison (PCMDI) and the World Climate Research Programme's Working Group on Coupled Modelling (WGCM) for producing, coordinating, and making available the MPI-ESM-LR and all other CMIP5 datasets. We are grateful for the the provided gridded observation data by the German Weather Service (DWD). Luzia Keupp is employed in the BigData@Geo project co-funded by the European Regional Development Fund (ERDF) under grant No. 20-3044-2-11.

Institutional Review Board Statement: Not applicable.

Informed Consent Statement: Not applicable.

Data Availability Statement: Not applicable.

Conflicts of Interest: The authors declare no conflict of interest.

\section{Appendix A. Coding Example}

The following section provides an overview of the interview analysis according to the Grounded Theory Methodology based on an interview excerpt. We worked with very detailed tables and either kept memos in separate documents or added them directly to the corresponding text passages, codes and concepts using the comment function. A major advantage of the manual editing of text segments is that content is internalized and independent cognitive associations to statements and facts are formed. Firstly, we break up the transcript into segments (see Figure A1) and paraphrase the material with appropriate codes or take out in vivo codes. Further, data on these codes and where they are found are captured in a table; see Table A1. Afterwards subcategories with the aim of synthesizing the meaning or content of the code are developed. The continuous writing of memos, "stop and memo" [53] accompanies the entire research process and takes into account the quality criterion "documentation". Here, individual analysis steps and derived theories are written and reflected intuitively. 
Table A1. Excerpt to illustrate open coding.

\begin{tabular}{|c|c|c|c|}
\hline Rows & Codes/Concepts & Categories & Memo \\
\hline 286 & $\begin{array}{l}\text { But awareness is being raised in various } \\
\text { training courses with interactive formats (119) }\end{array}$ & raising awareness (XVII) & \\
\hline $\begin{array}{l}287 \\
286-287 \\
288 \\
288-289 \\
289-290\end{array}$ & $\begin{array}{l}\text { switching off, which goes to switch off (120) } \\
\text { programming light switches (122) } \\
\text { it works (121) } \\
\text { automatic switching off (123) } \\
\text { conscious switch on (124) }\end{array}$ & $\begin{array}{l}\text { so all processes } \\
\text { that arise in our company } \\
\text { we naturally try to align } \\
\text { with this climate mitigation (XVII) }\end{array}$ & $\begin{array}{l}\text { Company dedicates to sustainability } \\
\text { earlier than industry-like } \\
\text { companies and sets } \\
\text { high targets, which are accompanied } \\
\text { by a high investment volume } \\
\text { and induce numerous changes } \\
\text { in (technical) building equipment, } \\
\text { processes and task areas }\end{array}$ \\
\hline $\begin{array}{l}290-291 \\
291\end{array}$ & $\begin{array}{l}\text { There are also some other } \\
\text { issues going on outside (125) } \\
\text { But this should be done more } \\
\text { often within the academy (126) }\end{array}$ & sustainability academy (I) & $\begin{array}{l}\text { The academy serves as a place } \\
\text { of learning and offers } \\
\text { the exchange and networking } \\
\text { with third party. A lot of information } \\
\text { and impulses for action } \\
\text { come from external sources and are } \\
\text { simply fed to us (Z128) }\end{array}$ \\
\hline
\end{tabular}

\section{Appendix A.1. Axial Coding}

The categories formed during open coding provide the basis for axial coding. First, for each interview, individual conspicuous categories are placed on a horizontal axle to examine the causal conditions, the context, the strategies and the consequences of this phenomenon [55]. Then, these so-called coding paradigms are transcribed across all interviews to show any kind of interrelationships and differences. A coding paradigm according to [53] is shown in Figure A1.

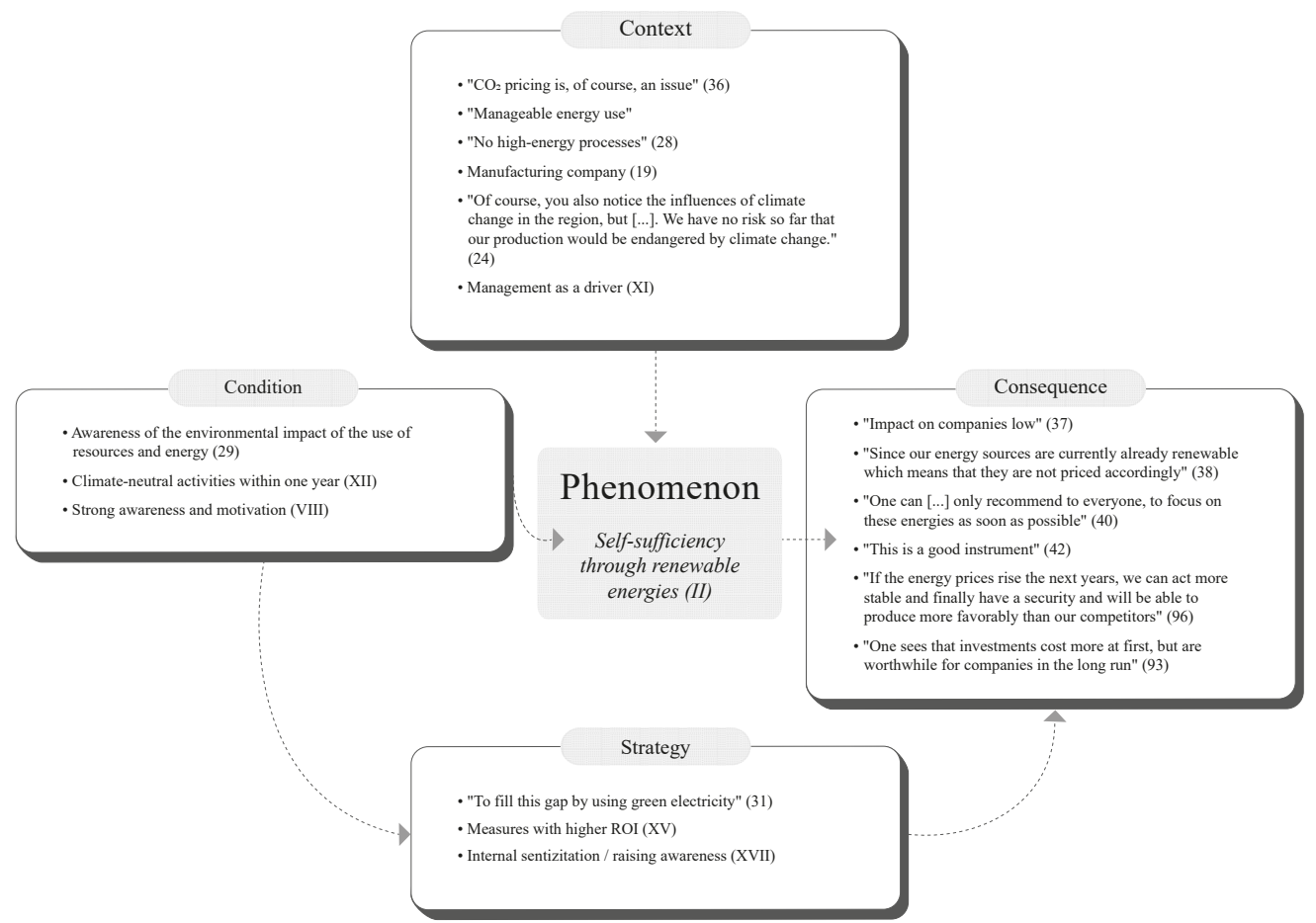

Figure A1. Coding paradigm. In the illustrated coding paradigm, the phenomenon or category: "Self-sufficiency through renewable energies" is placed on the horizontal axle and examined with regard to the causal conditions and context, resulting strategies and consequences. 


\section{Appendix A.2. Selective Coding}

In the selective coding phase, categories are condensed by identifying relationships and differences. Further, assumptions based on interview statements and core categories are identified which can be used to link the other subcategories. Selective coding is a process of continuous comparison and interpretation to form a dense network that contains the core categories and on the basis of which the research questions can be answered. This step characterizes the most complex process of the Grounded Theory.

\section{Appendix B. Interview Guidelines}

To conduct the interviews, a semi-structured guideline was developed. Outlining a set of questions and order [61] left a large open space and the guideline works rather as a conversation guide. The included questions were designed to be explorative and open, to encourage the interviewees to reveal specific experiences or knowledge. Additionally, detailed questions are included in the interview guide, which may be asked situationally. The following section contains two interview guides.

\section{Appendix B.1. Interview Guide on Climate Adaptation in Manufacturing Companies from the Perspective of EMAS Experts}

With the first access, experts of the environmental management system EMAS were interviewed (a managing director and a consultant of a governmental consulting institute). The purpose was to provide an external perspective on the behavior and challenges of companies towards climate change. In addition, further details regarding the effort and advantages of the certification should be discussed.

\section{Appendix B.1.1. I. Introduction Questions Climate Change}

1. Where do you see the biggest challenges/risks of climate change for manufacturing companies?

- Are there aspects that you consider to be positive/opportunities?

2. How do you define climate adaptation?

- On average, how progressive do you think climate adaptation is among manufacturing companies in Mainfranken? (e.g., scale: not at all, somewhat, very well), feel free to give reasons.

\section{Appendix B.1.2. II. Specifically Climate Change and EMAS}

1. Which attitudes do manufacturing companies have regarding environment, greenhouse gas emissions, climate mitigation etc., before the registration?

- What is their level of knowledge in this regard? (School grade 1-6)

- What is the most amount of work still to be done? (Scale from $0-100 \%$ )

- Where and what are the biggest "working areas" / uncertainties?

2. How do you proceed to be able to understand the company and organizational structures? (and if not mentioned, what areas are being considered and why)?

- $\quad$...to then ultimately identify where climate adaptation is possible/necessary?

- In your experience, what are the barriers?

- In your experience, what are "great" promoters (e.g., actual exposure or positives, such as motivated employees)?

Appendix B.1.3. III. Initialization of EMAS

1. Do the manufacturing companies discuss/plan an EMAS registration out of their own intention and values?

- What would be other reasons e.g., economic/political? (Claims stakeholders, KSG). 
- Which resources do the companies have to invest (time, personnel, financial)?

- (Query: which of the three expressions in percentage terms most?)

- $\quad$ (Asked back: investing resources are mostly critical for companies?)

- Is there government funding that supports the EMAS process?

Appendix B.1.4. IV. Experiences EMAS

1. What changes does EMAS registration induce in manufacturing organizations?

Appendix B.1.5. V. Conclusion

1. Thank you very much for the interview.

- Would you like to mention any aspects I did not ask specific questions about?

Appendix B.2. Interview Guide on Climate Adaptation in EMAS Certified Manufacturing Companies

The second access was used to interview managing directors, environmental managers, etc., of companies, preferably manufacturing companies, which are EMAS certified. Here, we followed the dynamic interview process and asked many questions outside of the guideline, as later the focus was more on examining organizational learning rather than the specific climate adaptation measures.

Appendix B.2.1. I. Introduction Questions about the Company's Conditions and the Respondent's Function in the Company

1. To start with, first I will ask you a few questions about your company and the framework conditions.

2. Please tell me your function at «company».

- In general, what are your duties or areas of responsibility?

3. What exactly does your company produce?

4. How do you define climate adaptation?

- What international locations do you have?

Appendix B.2.2. II. Understanding of Climate Change and Being Affected by It

1. Now I would like to talk more about the effects of climate change and concrete adaptation strategies.

2. To what extent are you currently or have you been confronted with the issue of climate change in the past?

- $\quad$ Please give me some examples of indirect or direct impacts of events.

- In which form/amount did damages occur?

3. What do you think are the environmental impacts of your company's activities?

4. What are the main difficulties or risks of climate change for your company in general?

- Which organizational area does this affect the most?

- In general terms, what would you consider to be a positive or an opportunity for your company?

5. Since when has climate adaptation been an issue for you?

- Who is responsible for the topic? [What is the process for developing strategies / identifying needs for action]?

Appendix B.2.3. III. Climate Change Adaptation Strategies

1. Which concrete climate adaptation measures do you implement (in the past, at present and in the future, e.g., with regard to building equipment)?

2. To what extent do you distinguish between climate adaptation and climate mitigation?

3. What are your strategic goals regarding climate change/adaptation/mitigation? 
4. If you have to rate your current climate adaptation strategies with school grades (1-6), which grade would it be?

- $\quad$ Please tell me issues that you rate as particularly positive.

- Please name issues that you think should be done better.

Appendix B.2.4. IV. Implementation of EMAS: Motivation and Requirements

1. I am asking you because your company is one of those companies in Main-Franconia that have had EMAS certification carried out.

2. What was the initial impulse to deal with EMAS in more detail? (How/Who)

- What were the concrete reasons for having an audit carried out?

3. What did the process of EMAS registration look like (time, costs and resources, from the first meeting to the certificate)?

- Which resource to be invested (time, costs, personnel or similar) was critical?

4. How does the registration affect the entire company? i.e., employees, stakeholders, etc.

Appendix B.2.5. V. Conclusions

1. What would you like to see from scientific or political consulting and information initiatives?

- Would you like to mention any aspects of your own that I did not ask specific questions about?

2. Thank you for the interview.

\section{References}

1. Statista. Dossier Klimawandel. 2020. Available online: https://de.statista.com/statistik/studie/id/41248/dokument/ klimawandel-statista-dossier / (accessed on 20 August 2021).

2. Tollefson, J. IPCC says limiting global warming to $1.5 \mathrm{C}$ will require drastic action. Nature 2018, 562, 172-173. [CrossRef] [PubMed]

3. Hina, T.; Adil, S.A.; Ashfaq, M.; Ahmad, A. Economic impact assessment of climatic change sensitivity in rice-wheat cropping system of Pakistan. Indian J. Sci. Technol. 2019, 12, 37. [CrossRef]

4. Mahammadzadeh, M.; Chrischilles, E.; Biebeler, H. Klimaanpassung in Unternehmen und Kommunen: Betroffenheiten, Verletzlichkeiten und Anpassungsbedarf; Number 83; IW-Analysen: Köln, Germany, 2013.

5. Hirschfeld, J.; Hansen, G.; Messner, D. Die klimaresiliente Gesellschaft-Transformation und Systemaenderungen. In Klimawandel in Deutschland; Springer Spektrum: Berlin/Heidelberg, Germany, 2017; pp. 315-324.

6. Department, S.R. $\mathrm{CO}_{2}$-Ausstoß Weltweit Bis 2019. 2021. Available online: https://de.statista.com/statistik/studie/id/41248/ dokument/klimawandel-statista-dossier/ (accessed on 20 August 2021).

7. BMU. Bundesministerium fur Umwelt, Naturschutz und nukleare Sicherheit. Broschure Nr. 10034. Klimaschutz in Zahlen. Fakten, Trends und Impulse deutscher Klimapolitik. 2020. Available online: https://www.bmu.de/publikation/klimaschutz-inzahlen-2020/ (accessed on 20 August 2021).

8. BMU. Bundesministerium fur Umwelt, Naturschutz und Nukleare Sicherheit. Treibhausgasemissionen Sinken 2020 um 8,7 Prozent. 2021. Available online: https:/ / www.bmu.de/publikation/klimaschutz-in-zahlen-2020/ (accessed on 20 August 2021).

9. Rauh, J.; Paeth, H. Anthropogener Klimawandel und Weinwirtschaft-Wahrnehmung und Anpassungsmaßnahmen fränkischer Winzer auf den Wandel klimatischer Bedingungen. Berichte Zur Dtsch. Landeskd. 2011, 85, 151-177.

10. Karg, L.; Wedler, M.; Blaschke, T.; Pielniok, D.; Sailer, M.; Giglmaier, S. Wuerzburg. 2021. Available online: https:// www.wuerzburg.de/media/www.wuerzburg.de/org/med_512829/415559_bericht_ikk_wuerzburg_130318.pdf (accessed on 20 August 2021).

11. Schönbein, D.; Keupp, L.; Paeth, H. Dossier Klimawandel. 2020. Available online: https://bigdata-at-geo.eu/klimabericht/\#/ (accessed on 20 August 2021).

12. Guilyardi, E.; Lescarmontier, L.; Matthews, R.; Point, S.P.; Rumjaun, A.B.; Schluepmann, J.; Wilgenbus, D. IPCC-Sonderbericht “1, $5{ }^{\circ} \mathrm{C}$ globale Erwärmung": Zusammenfassung für Lehrerinnen und Lehrer. 2019. Available online: https://www.sonnentaler. net/dokumentation/ipcc-berichte/1,5-grad-bericht/ (accessed on 20 August 2021).

13. Matthias, B. Statista. 2020. Available online: https://de.statista.com/infografik/22090/klimaschutz-investitionen-desproduzierenden-gewerbes-in-deutschland/ (accessed on 20 August 2021).

14. Heilmann, A.; Pundt, H. Kommunale Anpassung an die Folgen des Klimawandels als Komponente einer Nachhaltigen Entwicklung. In Forschung für Nachhaltigkeit an Deutschen Hochschulen; Springer: Berlin/Heidelberg, Germany, 2016; pp. 223-244. 
15. Bardt, H. Kommunale Umweltpolitik zwischen strategischer Planung und Pragmatismus-das Beispiel der Anpassung an den Klimawandel. In Nachhaltiges Wirtschaften im Digitalen Zeitalter; Springer: Berlin/Heidelberg, Germany, 2018 ; pp. 323-332.

16. Marx, A. Klimaanpassung in Forschung und Politik; Springer: Berlin/Heidelberg, Germany, 2017.

17. Meinel, U.; Schüle, R. The difficulty of climate change adaptation in manufacturing firms: Developing an action-theoretical perspective on the causality of adaptive inaction. Sustainability 2018, 10, 569. [CrossRef]

18. Meinel, U.; Höferl, K.M. Non-adaptive behavior in the face of climate change: First insights from a behavioral perspective based on a case study among firm managers in alpine Austria. Sustainability 2017, 9, 1132. [CrossRef]

19. Kanyama, A.C.; Kanyama, K.C.; Wester, M.; Snickare, L.; Söderberg, I.L. Climate change mitigation efforts among transportation and manufacturing companies: The current state of efforts in Sweden according to available documentation. J. Clean. Prod. 2018, 196, 588-593. [CrossRef]

20. Nicolletti, M.; Lutti, N.; Souza, R.; Pagotto, L. Social and organizational learning in the adaptation to the process of climate change: The case of a Brazilian thermoplastic resins and petrochemical company. J. Clean. Prod. 2019, 226, 748-758. [CrossRef]

21. Bianchi, G.; Testa, F.; Boiral, O.; Iraldo, F. Organizational Learning for Environmental Sustainability: Internalizing Lifecycle Management. Organ. Environ. 2021. [CrossRef]

22. Hurrelmann, K.; Becker, L.; Fichter, K.; Mahammadzadeh, M.; Seela, A. Klima-LO: Klimaanpassungsmanagement in Lernenden Organisationen. Oldenburg, Köln. Unter. 2018. Available online: https://uol.de/innovation/forschung/klima-lo (accessed on 20 August 2021).

23. Kind, C.; Protze, N.; Savelsberg, J.; Lühr, O.; Ley, S.; Lambert, J.; Prognos, A. Entscheidungsprozesse zur Anpassung an den Klimawandel in Kommunen. Clim. Chang. 2015, 4, 2015.

24. Linnenluecke, M.K.; Griffiths, A.; Winn, M.I. Firm and industry adaptation to climate change: A review of climate adaptation studies in the business and management field. Wiley Interdiscip. Rev. Clim. Chang. 2013, 4, 397-416. [CrossRef]

25. Ameling, D.; Bajorat, B.; Brinker, W.; Burger, R.; Cramer, H.J.; von Dohnanyi, K.; Ferkel, H.; Gedaschko, A.; Glatzel, G.; Graner, A.; et al. Anpassungsstrategien in der Klimapolitik; Springer Science + Business Media: Berlin/Heidelberg, Germany, 2012.

26. Rosengren, L. 10 Capturing adaptation opportunities. In The Catalytic Effects of DFI Investment-Gender Equality, Climate Action and the Harmonisation of Impact Standards; 2021. p. 70. Available online: https://cdn.odi.org/media/documents/ODI_EDFI_essay_ series_final.pdf (accessed on 20 August 2021).

27. Mason, C.; Hobday, A.J.; Alderman, R.; Lea, M.A. Climate adaptation interventions for iconic fauna. Conserv. Sci. Pract. 2021, 3, e434. [CrossRef]

28. Argyris, C. Single-loop and double-loop models in research on decision making. Adm. Sci. Q. 1976, 21, 363-375. [CrossRef]

29. Orsato, R.J.; Barakat, S.R.; de Campos, J.G.F. Organizational adaptation to climate change: Learning to anticipate energy disruptions. Int. J. Clim. Chang. Strateg. Manag. 2017, 9. [CrossRef]

30. Gephart, M.A.; Marsick, V.J. Strategic Leverage Through Learning@). In Strategic Organizational Learning; Springer: Berlin/Heidelberg, Germany, 2016; pp. 7-17.

31. Göhlich, M.; Schröer, A.; Weber, S.M. Organisationspädagogik-erziehungswissenschaftliche Subdisziplin und pädagogisches Arbeitsfeld. In Handbuch Organisationspädagogik; Springer: Berlin/Heidelberg, Germany, 2018; pp. 1-13.

32. Argyris, C.; Schön, D.A. Organizational learning: A theory of action perspective. Reis 1997, 77-78, 345-348. [CrossRef]

33. March, J.G.; Olsen, J.P. The uncertainty of the past: Organizational learning under ambiguity. Eur. J. Political Res. 1975, 3, 147-171. [CrossRef]

34. Senge, P.M. The fifth discipline. Meas. Bus. Excell. 1997, 1, 46-51. [CrossRef]

35. Pätzold, H. Das organisationale Lerndreieck-eine lerntheoretische Perspektive auf organisationales Lernen. Z. für Weiterbildungsforschung 2017, 40, 41-52. [CrossRef]

36. Schlüter, A. Individuelle Akteure als Gegenstand der Organisationspädagogik. In Handbuch Organisationspädagogik; Springer: Berlin/Heidelberg, Germany, 2018; pp. 407-417.

37. Marsick, V.J.; Watkins, K.E. Demonstrating the value of an organization's learning culture: The dimensions of the learning organization questionnaire. Adv. Dev. Hum. Resour. 2003, 5, 132-151. [CrossRef]

38. Schein, E.H. Organizational Culture and Leadership; John Wiley \& Sons: Hoboken, NJ, USA, 2010; Volume 2.

39. Gherardi, S.; Nicolini, D. Learning in a constellation of interconnected practices: Canon or dissonance? J. Manag. Stud. 2002, 39, 419-436. [CrossRef]

40. Schaltegger, S.; Hansen, E.G.; Lüdeke-Freund, F. Business models for sustainability: Origins, present research, and future avenues. Organ. Environ. 2016, 29,3-10. [CrossRef]

41. Daddi, T.; Todaro, N.M.; De Giacomo, M.R.; Frey, M. A systematic review of the use of organization and management theories in climate change studies. Bus. Strategy Environ. 2018, 27, 456-474. [CrossRef]

42. Jacob, D.; den Hurk, B.J.J.M.V.; Andræ, U.; Elgered, G.; Fortelius, C.; Graham, L.P.; Jackson, S.D.; Karstens, U.; Köpken, C.; Lindau, R.; et al. A comprehensive model inter-comparison study investigating the water budget during the BALTEX-PIDCAP period. Meteorol. Atmos. Phys. 2001, 77, 19-43. [CrossRef]

43. Jacob, D. A note to the simulation of the annual and inter-annual variability of the water budget over the Baltic Sea drainage basin. Meteorol. Atmos. Phys. 2001, 77, 61-73. [CrossRef] 
44. Jacob, D.; Petersen, J.; Eggert, B.; Alias, A.; Christensen, O.B.; Bouwer, L.M.; Braun, A.; Colette, A.; Déqué, M.; Georgievski, G.; et al. EURO-CORDEX: New high-resolution climate change projections for European impact research. Reg. Environ. Chang. 2014, 14, 563-578. [CrossRef]

45. Jacob, D.; Kottmeier, C.; Petersen, J.; Rechid, D.; Teichmann, C. Regionale klimamodellierung. In Klimawandel in Deutschland; Springer Spektrum: Berlin/Heidelberg, Germany, 2017; pp. 27-35.

46. Service, D.G.W. Grids of Monthly Averaged Daily Air Temperature (2 m) over Germany. Data set. 2021. Available online: https:// opendata.dwd.de/climate_environment/CDC/grids_germany/monthly/air_temperature_mean/ (accessed on 20 August 2021)

47. Taylor, K.E.; Stouffer, R.J.; Meehl, G.A. An Overview of CMIP5 and the Experiment Design. Bull. Am. Meteorol. Soc. 2012, 93, 485-498. [CrossRef]

48. IPCC. Climate Change 2013: The Physical Science Basis. Contribution of Working Group I to the Fifth Assessment Report of the Intergovernmental Panel on Climate Change; Cambridge University Press: Cambridge, UK, 2013.

49. Vuuren, D.P.V.; Edmonds, J.; Kainuma, M.; Riahi, K.; Thomson, A.; Hibbard, K.; Hurtt, G.C.; Kram, T.; Krey, V.; Lamarque, J.F.; et al. The representative concentration pathways: An overview. Clim. Chang. 2011, 109, 5-31. [CrossRef]

50. Mogale, R. "It is not the strongest of the species that survives, nor the most intelligent. It is the one that is most adaptable to change." Charles Darwin. SA Pharm. J. 2018, 85, 61.

51. Riahi, K.; Rao, S.; Krey, V.; Cho, C.; Chirkov, V.; Fischer, G.; Kindermann, G.; Nakicenovic, N.; Rafaj, P. RCP 8.5-A scenario of comparatively high greenhouse gas emissions. Clim. Chang. 2011, 109, 33-57. [CrossRef]

52. Schwalm, C.R.; Glendon, S.; Duffy, P.B. RCP8.5 tracks cumulative $\mathrm{CO}_{2}$ emissions. Proc. Natl. Acad. Sci. USA 2020, 117, 19656-19657. [CrossRef] [PubMed]

53. Glaser, B.G.; Strauss, A.L. Grounded Theory: Strategien Qualitativer Forschung; Huber: Bern, Switzerland, 2010.

54. Corbin, J.; Strauss, A. Theoretical sampling. Basics Qual. Res. 2008. [CrossRef]

55. Böhm, A. Grounded Theory-Wie aus Texten Modelle und Theorien Gemacht Werden; UVK Universitätsverlag: Konstanz, Germany, 1994; Volume 14.

56. Mayring, P. Qualitative content analysis-research instrument or mode of interpretation. Role Res. Qual. Psychol. 2002, 2, 139-148.

57. Pidgeon, N.F.; Turner, B.A.; Blockley, D.I. The use of grounded theory for conceptual analysis in knowledge elicitation. Int. J. Man-Mach. Stud. 1991, 35, 151-173. [CrossRef]

58. Engel, N. Qualitative Methodologie in der Organisationspädagogik. In Handbuch Organisationspädagogik; Springer: Berlin/Heidelberg, Germany, 2018; pp. 271-282.

59. eurostat. Glossary Enterprise Size. 2021. Available online: https://ec.europa.eu/eurostat/statistics-explained/index.php?title= Glossary:Enterprise_size (accessed on 20 August 2021).

60. Göhlich, M.; Zirfas, J. Lernen: Ein Pädagogischer Grundbegriff; W. Kohlhammer Verlag: Stuttgart, Germany, 2007.

61. Liebold, R.; Trinczek, R. Experteninterview. In Handbuch Methoden der Organisationsforschung-Quantitative und Qualitative Methoden; Kühl, S., Strodtholz, P., Traffertshofer, A.H., Eds.; VS Verlag für Sozialwissenschaften: Wiesbaden, Germany, 2009. 